\title{
Clinical Research Made Easy: A guide to publishing in medical literature
}

\section{By Mohit Bhandari and Parag Sancheti Jaypee Brothers and Medical Publishers (P) Ltd.}

This book covers the basic issues related to clinical research in medicine. It is written in a very simple language and in a question-answer format. This covers most of the questions which may come to mind while planning and conducting clinical research. The difficult terminology and concepts are well-explained and each chapter starts with clear learning objectives and ends with point-wise conclusions and references for additional reading. The book has 28 chapters with four sections. Section I covers the concept of evidence-based medicine and explains the hierarchy of the evidence. Section II describes the principles of clinical research with adequate discussion around various types of studies for different levels of evidence. This section also covers economic analysis, diagnostic test study, and reliability study. Section III focuses on the practice of clinical research and describes the steps of making a comprehensive research proposal including sample size and budgeting for various types of studies. Section IV covers the basics of statistical principles used for medical research. The last few chapters of the book discuss the art of making a good abstract for submission at clinical meetings, how to prepare an oral and poster presentation, as well as a manuscript for publication.

I firmly believe that research is an integral component of good patient care, as well as a successful clinical and academic practice. This book is useful not only to trainees but also to practicing Orthopaedic Surgeons. I would recommend that it should be available in personal and institutional libraries.

Athanasios I Tsirikos

Scottish National Spine Deformity Center, Royal Hospital for Sick Children, Sciennes Road, Edinburgh, EH9 1LF, U.K.

E-mail: atsirikos@hotmail.com 